\title{
The Erosive Potential of Some Flavoured Waters
}

\author{
Jeremy Rees'a, BDS, MScD, FDSRCS (Ed), PhD \\ Theresa Loyn ${ }^{a}$, FIBMS \\ Lindsay Hunter ${ }^{\mathrm{b}}$, BDS, MScD, FDSRCS (Ed), PhD \\ Leili Sadaghiania, DDS, MFDS (Ed) \\ Alan Gilmour ${ }^{a}$, BDS, MScD, FDSRCS (Ed), PhD
}

\section{ABSTRACT}

Objectives: To assess the erosive potential of a number of readily available flavoured waters in the laboratory.

Methods: The erosive potential was assessed by measuring the $\mathrm{pH}$, neutralisable acidity and ability to erode enamel. These were compared to an orange juice positive control.

Results: The $\mathrm{pH}$ of the flavoured waters ranged from 2.64-3.24 with their neutralisable acidity ranging from 4.16-16.30 mls of $0.1 \mathrm{M} \mathrm{NaOH}$. The amount of enamel removed following 1-hour immersion in the drinks ranged from 1.18-6.86 microns. In comparison, the orange juice control had a pH of 3.68, a neutralisable acidity of $19.68 \mathrm{mls}$ of $0.1 \mathrm{M} \mathrm{NaOH}$ and removed 3.24 microns of enamel.

Conclusions: Many of the flavoured waters tested were found to be as erosive as orange juice. This information will be of use to clinicians when counselling patients with tooth surface loss. (Eur J Dent 2007;1:5-9)
\end{abstract}

Key words: Dental erosion; Dental enamel; Non-carious tooth surface loss

\section{INTRODUCTION}

Dental erosion is defined as an irreversible loss of dental hard tissues due to a chemical process without the involvement of microorganisms. ${ }^{1}$ This process may be caused by extrinsic or intrinsic agents. Extrinsic agents include acidic food stuffs, beverages, snacks or following environmental exposure to acidic agents..$^{2,3}$ Intrinsic causes are associated with gastric acid and may present intra-orally following vomiting, regurgitation, gastro-oesophageal reflux or rumination. ${ }^{4}$

The evidence linking erosion with diet is based on a number of case reports and a few epidemiological studies. Millward et al ${ }^{5}$ examined 101 school children and found a high level of erosion associated with the consumption of soft drinks,

$\square$ a Department of Adult Dental Health

${ }^{b}$ Department of Child Dental Health, Dental School, Wales College of Medicine, Cardiff University, Heath Park, Cardiff, CF14 4XY, UK.

$\square$ Corresponding author: Prof J. S. Rees

Department of Adult Dental Health, Dental School, Wales College of Medicine,

Cardiff University, Heath Park, Cardiff, CF14 4XY UK Tel: + $442920746557 \quad$ Fax: + 442920743120

E-mail: reesjs1dcardiff.ac.uk particularly carbonated beverages. Jarvinen et $\mathrm{al}^{6}$ carried out the only case-controlled study and found that the risk for erosion was increased if citrus fruit was consumed more than twice daily or if sports drinks were consumed more than once a week.

Sales of soft drinks within the UK have increased over seven fold since $1950^{7}$ and Coca-Cola ${ }^{\circledR}$ is the biggest selling brand in the UK today, while PepsiCola ${ }^{\circledR}$ is the eighth biggest brand. ${ }^{8}$ Sales of mineral waters have also increased rapidly over the last decade in a similar fashion to soft drinks. Recently manufacturers have introduced flavoured waters to the market and this sector has grown rapidly with $25 \%$ of adults in the UK consuming these drinks. ${ }^{9}$ The term flavoured water is a misnomer as under bottled water regulations nothing can be added to water, except carbon dioxide for carbonated bottled waters. As soon as any additional ingredient is added, whether it is a colour, flavour or sweetener then the product becomes a soft drink. ${ }^{10}$ However, for the sake of clarity the term 'flavoured water' will be used throughout this article as it is in common usage.

The $\mathrm{pH}$ of still mineral waters has been found to be close to neutrality, while the $\mathrm{pH}$ of carbon- 
ated water is slightly more acidic at around 5.2.11 The effect of still and carbonated mineral water on powdered enamel has been assessed using spectroscopy. ${ }^{11}$ It was found that these drinks had little erosive effect on enamel and carbonated water produced a slightly greater dissolution effect compared to still water, but this is very unlikely to be of clinical significance.

The $\mathrm{pH}$ of some flavoured waters were found to be more acidic than plain still or carbonated waters, with a pH of around 3.3. ${ }^{11}$ However, the effect of these drinks on enamel was not assessed.

The aim of this study was to compare a number of commercially available flavoured waters and compare these with orange juice. The hypothesis used in this study was that the flavoured waters would not be more erosive than orange juice.

\section{MATERIALS AND METHODS}

The flavoured waters chosen for inclusion in this study are listed in Table 1. These drinks were chosen as they were readily available to the public. Three of the drinks were carbonated and these are indicated with an asterix in Table 1. The remaining drinks were still water products with no carbonation.

\section{Initial pH}

The $\mathrm{pH}$ of each of the drinks was tested using an electronic $\mathrm{pH}$ meter (Model 701A, Orion Re- search Inc., Waltham, MA, USA) at $37^{\circ} \mathrm{C}$ on a heated magnetic stirrer. The $\mathrm{pH}$ meter was calibrated using test solutions of known pH (Fisher Scientific International, Loughborough, UKJ before testing the drinks. Each drink was tested using five different samples.

\section{Neutralisable acidity}

The neutralisable acidity of each drink was tested by placing $20 \mathrm{mls}$ of the drink in a glass beaker placed in a thermostatically controlled water bath held at $37^{\circ} \mathrm{C}$. $0.1 \mathrm{M}$ sodium hydroxide solution was gradually added to the drink sample and the $\mathrm{pH}$ rise was continuously monitored until the $\mathrm{pH}$ increased to neutrality. Each sample was stirred continuously as the solution of sodium hydroxide was added. The volume of sodium hydroxide required to increase the $\mathrm{pH}$ of the sample to neutrality was noted; this was repeated five times for each drink.

\section{Enamel erosion}

All measurements of enamel loss were made using profilometry according to the method of West. ${ }^{12}$ The source of enamel was extracted unerupted third molar teeth from individuals residing in a region with unfluoridated drinking water. Thus the level of fluoride incorporation into enamel was anticipated to be low, but was not further characterised. The specimens were sectioned longitudi-

Table 1. Drink contents according to manufacturers' information.

\begin{tabular}{ll}
\hline Flavoured water & Contents \\
\hline $\begin{array}{l}\text { Volvic Touch of Fruit still lemon } \\
\text { and lime }\end{array}$ & Mineral water (92\%), sugar, citric acid, lemon and lime natural flavours \\
$\begin{array}{ll}\text { Boots Shapers still cranberry } \\
\text { juice spring water }\end{array}$ & $\begin{array}{l}\text { Spring water, apple juice from concentrate (13.5\%), cranberry juice from } \\
\text { concentrate (6.5\%), citric acid, flavourings, preservatives(E242, potassium } \\
\text { sorbate, sodium benzoate), stabiliser (E466), sweeteners (sucralose), anti- } \\
\text { oxidant lascorbic acid), colour lanthocyanins), Vitamins E, B3, B6 and B12 }\end{array}$
\end{tabular}

Boots Shapers sparkling cloudy lemonade spring water*

Boots Shapers still Floridian orange juice spring water

Volvic Touch of Fruit still orange and peach

Waitrose grapefruit spring water drink*

Bottlegreen presselight elderflower*
Carbonated spring water, lemon fruit from concentrate (3\%), lemon juice from concentrate $(1 \%)$, citric acid, flavourings, preservatives (potassium sorbate, sodium benzoate, sulphur dioxide), sweeteners (sucralose, acesulfame Kl

Carbonated spring water, Floridian orange juice from concentrate (18\%), fruit from concentrate (2.5\%), citric acid, flavourings, preservatives (E242, potassium sorbate, sodium benzoate), sweetener (sucralose), vitamins C, E and $A$

Mineral water (92\%), sugar, citric acid, orange and peach natural flavours

Carbonated spring water, grapefruit juice from concentrate, fructose, citric acid, flavourings, sweetener (aspartame), preservative (sodium benzoate)

Carbonated spring water, cane sugar, elderflowers, citric acid, ascorbic acid, preservative (sodium benzoate), sweetener (aspartame)

* indicates carbonated drink 
nally and embedded in a low exotherm epoxy resin (Stycast 1266, Emerson \& Cuming, Westerlo, Belgium). The outer surface of the enamel samples were lightly ground with first 600-grit and then 1200-grit abrasive discs (Kemet International Ltd., Parkwood Trading Estate, Maidstone, Kent) to produce a flat surface. Three baseline readings using a profilometer (Planer Products Ltd., Sunbury on Thames, UK) were recorded for each enamel sample. Only samples with a stylus deflection of less than an average $\pm 0.30 \mu \mathrm{m}$ deflection were used in the study. The diamond stylus had a tip radius of $20 \mu \mathrm{m}$ with a head velocity of $10 \mathrm{~mm} / \mathrm{min}$. The force of the stylus varied linearly with deflection at a rate of $8 \mathrm{mg} / \mu \mathrm{m}$ up to a maximum of $1 \mathrm{~g}$ at $100 \mu \mathrm{m}$.

After baseline profiles were determined in duplicate, enamel samples were taped to expose a 2 $\mathrm{mm}$ width of enamel lapproximate enamel area of $10 \mathrm{~mm}^{2}$ ). Five enamel specimens were exposed to $250 \mathrm{mls}$ of each drink and stirred in a thermostatically controlled water bath at $37^{\circ} \mathrm{C}$ for one hour. Following exposure, the enamel specimens were rinsed in water, dried and the tapes removed. Surface enamel loss was measured on the profilometer in triplicate, with the amount of enamel loss recorded in micrometers. Averages were calculated from triplicate measurements.

Five enamel specimens were also immersed in Tropicana ${ }^{\mathrm{TM}}$ brand orange juice for one hour as a positive control and in distilled water as a negative control.

Statistical analysis of the results for $\mathrm{pH}$, neutralisable acidity and enamel erosion was carried out using analysis of variance followed by Tukey's test. The threshold for statistical significance was set at $P<.05$.

\section{RESULTS}

The results for the initial $\mathrm{pH}$ values are given in Table 2. The $\mathrm{pH}$ of the flavoured waters tested ranged from 2.64-3.24 compared to a value of 3.68 for orange juice.

The results for the neutralisable acidity values are given in Table 2. These values ranged from $4.16 \mathrm{mls}$ for Volvic Touch of Fruit Still Orange and Peach to $16.30 \mathrm{mls}$ for Boots sparkling cloudy lemonade spring water. The positive control orange juice had the highest neutralisable acidity value of $19.68 \mathrm{mls}$.

The amount of enamel lost following immersion in the various drinks tested is shown in Table 2. The amount of enamel removed, ranged from 1.18 to $6.86 \mu \mathrm{m}$. In comparison, the orange juice positive control produced a mean surface loss of $3.34 \mu \mathrm{m}$. Two drinks produced significantly lower levels of enamel erosion; Volvic orange and peach and the elderflower drink. The values for the Volvic orange and peach were significantly lower than Volvic lemon and lime $(P<.01)$, cranberry $(P<.001)$, Boots lemonade $(P<.05)$, Boots orange juice $(P<.001)$ and Waitrose grapefruit $(P<.005)$.

The values for the elderflower drink were significantly lower than the Volvic lemon and lime $(P<.001)$, cranberry $(P<.001)$, Boots lemonade $(P<.001)$ and Boots orange juice $(P<.001)$.

\section{DISCUSSION}

The $\mathrm{pH}$ values for all the flavoured waters tested fell within a narrow band of 2.64-3.24 and all were slightly more acidic than the control orange juice. Although the values were numerically similar it must be remembered that $\mathrm{pH}$ is a logarithmic scale, so that small changes in $\mathrm{pH}$ values equate to larger changes in the hydrogen ion concentration. Previous studies have shown that the $\mathrm{pH}$ values of both still and carbonated bottled wa-

Table 2. Initial pH value, neutralisable acidity and enamel erosion values (SD in parentheses).

\begin{tabular}{lccc}
\hline Drink & $\mathbf{p H}$ & $\begin{array}{c}\text { Neutralisable } \\
\text { acidity (mls) }\end{array}$ & $\begin{array}{c}\text { Enamel erosion } \\
\text { (microns) }\end{array}$ \\
\hline Volvic Touch of Fruit still lemon and lime & $2.64(0.05)$ & $7.20(0.18)$ & $5.00(1.16)$ \\
Boots Shapers still cranberry juice spring water & $3.14(0.05)$ & $11.02(0.07)$ & $6.86(1.20)$ \\
Boots Shapers sparkling cloudy lemonade spring water & $2.78(0.04)$ & $16.30(0.09)$ & $6.29(0.35)$ \\
Boots Shapers still Floridian orange juice spring water & $3.24(0.05)$ & $11.6(0.22)$ & $5.34(2.46)$ \\
Volvic Touch of Fruit still orange and peach & $2.82(0.07)$ & $4.16(0.10)$ & $2.01(0.54)$ \\
Waitrose grapefruit spring water drink & $2.74(0.05)$ & $14.04(0.16)$ & $4.43(0.96)$ \\
Bottlegreen presselight elderflower & $3.04(0.05)$ & $13.62(0.27)$ & $1.18(0.14)$ \\
Tropicana natural orange juice & $3.68(0.04)$ & $19.68(0.31)$ & $3.24(0.62)$ \\
\hline
\end{tabular}


ters lie close to neutrality ${ }^{10,11}$ but the much more acidic values found in this study of less than 3.5 suggest that flavoured waters are potentially more erosive than their non-flavoured counterparts. Furthermore, the critical $\mathrm{pH}$ below which enamel begins to erode significantly is $4.5 .^{13}$ This is presumably due to the addition of fruit extracts as flavouring agents. These are high in naturally occurring fruit acids, such as citric acid, used as flavouring agents. Some manufacturers also add citrate based compounds to enhance the shelf life and this adds to the acidic burden of these drinks.

However, $\mathrm{pH}$ measurement of a drink does not give the whole picture ${ }^{14}$ and one must also consider the neutralisable acidity which gives a measure of all the free hydrogen ions available to cause erosion. The neutralisable acidity values of the flavoured waters varied more widely from $4.16 \mathrm{mls}$ of $0.1 \mathrm{M} \mathrm{NaOH}$ for Volvic still orange and peach to $16.3 \mathrm{mls}$ for Boots cloudy lemonade spring water drink. The reasons for this wide variation in these values are not immediately obvious and it is difficult to form an informed opinion as the product labelling does not give any percentages or concentrations for the components of the drinks. In comparison, the neutralisable acidity of the control orange juice was slightly higher than any of the flavoured waters tested at $19.68 \mathrm{mls}$.

The range of values for the neutralisable acidity of the flavoured waters is broadly comparable to other drinks that have been evaluated including white wine, alcopops and fruit teas (Table 3).

The values for the enamel erosion also var-

Table 3. Neutralisable acidity values of other types of drinks.

\begin{tabular}{lc}
\hline Drink & $\begin{array}{c}\text { Neutralisable acidity } \\
\text { (mls } \mathbf{0 . 1 M ~ N a O H ) ~}\end{array}$ \\
\hline Alcopops & 19 \\
White wine & $15.4-23.1 \mathrm{mls}$ \\
Ciders $^{21}$ & $9.4-27.1 \mathrm{mls}$ \\
Fruit teas $^{22}$ & $14.5-21.5 \mathrm{mls}$ \\
Sports drinks $^{23}$ & $3.5-60.3 \mathrm{mls}$ \\
\hline
\end{tabular}

Table 4. Concentration of malic and citric acids found in various fruit juices (mg per $100 \mathrm{gms}$ of fruit).$^{24}$

\begin{tabular}{lccc}
\hline Fruit juice & Malic acid & Citric acid & $\begin{array}{c}\text { Total acid } \\
\text { content }\end{array}$ \\
\hline Cranberry & 100 & 1560 & 15 \\
Grapefruit & 0 & 1460 & 1460 \\
Lemon & 290 & 6080 & 6370 \\
Orange & Trace & 980 & 980 \\
Elderflower & 66 & 0 & 66
\end{tabular}

ied quite widely from $1.18 \mu \mathrm{m}$ for the elderflower product to $6.28 \mu \mathrm{m}$ for the lemonade based product and $6.86 \mu \mathrm{m}$ for the cranberry based product. These values probably reflect the amount of naturally occurring fruit acids in the parent product. Elderflowers do not have a high concentration of fruit acids (Table 4), whereas lemons and cranberries both have large amounts of citric acid and it is this that probably accounts for the large amounts of erosion recorded.

The positive control, orange juice, removed $3.24 \mu \mathrm{m}$ of enamel and this is typical of most orange juices that tend to remove 3-4 $\mu \mathrm{m}$ of enamel in one hour in a laboratory test.

Apart from the elderflower product and Volvic orange and peach, all the other flavoured waters were capable of producing large amounts of enamel erosion. However, the erosion results of this study must be interpreted with a certain degree of caution as clinically the enamel surface will be covered by a protective pellicle and/or plaque layer and the tooth surface will also be subject to the flushing, buffering and remineralising effects of saliva. ${ }^{15,16}$ A further factor to consider is the clearance rates of these drinks from the mouth. ${ }^{17}$ Oral clearance of drinks may well be related to their viscosity ${ }^{17}$ and although this was not measured in this study, being water based, these drinks had a low viscosity.

Finally, this study was deliberately carried out at $37^{\circ} \mathrm{C}$ to allow comparison with previous work (Table 3). However, these sports drinks are usually consumed cold at around $5^{\circ} \mathrm{C}$ and the drinks will therefore have fewer dissociated $\mathrm{H}^{+}$ions and therefore produce less erosion. ${ }^{18}$

\section{CONCLUSIONS}

In spite of the limitations of this simple in vitro study, many of these flavoured waters may contribute to erosion in patients who are either susceptible to erosion or use these drinks on a daily or more regular basis.

\section{REFERENCES}

1. Eccles JD. Tooth surface loss from abrasion, attrition and erosion. Dent Update 1982;35:373-381.

2. Eccles JD, Jenkins WG. Dental erosion and diet. $J$ Dent 1974;2:153-159.

3. Asher C, Read MJF. Early enamel erosion in children associated with the excessive consumption of citric acid. $\mathrm{Br}$ Dent $J$ 1987;162:384-387.

4. Järvinen VK, Rytömaa I, Heinonen OP. Risk factors in dental erosion. J Dent Res 1991;70:942-947.

5. Millward A, Shaw L, Smith AJ, Rippin JW, Harrington E. The distribution and severity of tooth wear and the relationship between erosion and dietary constituents in a group of children. Int J Paediatr Dent 1994;4:151-156.

6. Shaw L, Smith AJ. Erosion in children: an increasing clinical problem? Dent Update 1994;21:103-106.

7. Rees JS. The role of drinks in tooth surface loss. Dent Up date 2004; $31: 318-326$ 
8. Bedwell R. Mineral water. British Market Research Bureau. www.bmrb.co.uk. Accessed 31.5.05.

9. British Soft Drinks Association. www.britishsoftdrinks. com. Accessed 31.5.05.

10. Parry J, Shaw L, Arnaud MJ, Smith AJ. Investigation of mineral waters and soft drinks in relation to dental erosion. $J$ Oral Rehabil 2001;28:766-772.

11. Edwards M, Creanor SL, Foye RH, Gilmour WH. Buffering capacities of soft drinks: the potential influence on dental erosion. J Oral Rehabil 1999;26:923-927.

12. West NX, Maxwell A, Hughes JA, Parker DM, Newcombe RG and Addy M. A method to measure clinical erosion: The effect of orange juice consumption on erosion of enamel. $J$ Dent 1998:26:329-335.

13. Mclntyre J.M. Erosion. Aust Prosthodont J 1992;6:17-25.

14. Barbour M, Rees JS. The laboratory assess ment of erosion. J Dent 2004;32:591-602.

15. Woltgens JHM, de Blick-Hogervorst JMA and Bervoets DJ. Enamel erosion and saliva. Clin Prev Dent 1985;7:8-10.

16. Hay DI, Pinsent BRW, Schram CJ, Wagg BJ. The protective effect of calcium and phosphate ions against acid erosion of dental enamel and dentine. Br Dent J 1962;112:283-287.

17. Milosevic, A. Sports drink hazard to teeth. Br J Sports Med 1997:31:28-30.

18. Barbour, ME, Hughes, JA, Parker, DM, Finke, M, Allen, GC, Addy, M. Enamel softening and erosion by soft drinks as a function of temperature and drink composition arch. Caries Res 2005 (In Press).

19. Rees JS, Burford K, Loyn T. The erosive potential of alcoholic lemonades. Eur J Pros Rest Dent 1999;6:161-164.

20. Rees JS, Hughes J, Innes C. An in vitro assessment of the erosive potential of some white wines. Eur J Pros Rest Dent 2002:10:37-42.

21. Rees JS, Griffiths J. An in vitro assessment of the erosive potential of conventional and white ciders. Eur J Pros Rest Dent 2002;10:167-171.

22. Phelan J, Rees JS. The erosive potential of some herbal teas. J Dent 2003; 31:241-246.

23. Rees JS, Loyn T, McAndrew R. The acidic and erosive potential of five sports drinks. Eur J Pros Rest Dent 2005;13: 186-190.

24. Documenta Geigy Scientific Tables. 5th Edition, pp. 230234. J.R. Geigy S.A., Basle, Switzerland, 1956. 